\title{
DO MOVING AVERAGE RULES MAKE PROFITS? A STUDY USING THE MADRID STOCK MARKET
}

\author{
IE Working Paper \\ WP 03 / 04 \\ Laura Núñez Letamendia \\ Instituto de Empresa \\ Serrano 105 \\ 28006 - Madrid \\ España \\ laura.nunez@ie.edu
}

$26 / 01 / 2004$

\begin{abstract}
Previous studies have reported mixed results with regard to the success of technical trading rules. Studies that provide positive evidence that simple technical trading rules generate valuable signals are [Brock, Lakonishok and Lebaron (1992), Karjalainen, R.E. (1994), Bessembinder and Chan (1995), Mills (1997), and Fernandez et al. (1999)]. Studies rejecting the utility of technical trading rules are [Hudson et al. (1996) or Allen, F. and Karjalainen R.E. (1999)]. A recent body of work has applied evolutionary algorithms to the design of trading rules [see Karjalainen (1994) and Allen and Karjalainen (1999) for genetic programming models of trading and Fernandez et al (2001) and Nuñez-Letamendia (2002) for genetic algorithms models]. The basic approach of these studies is to choose trading rules based on an genetic optimisation procedure using in-sample-data and then testing the performance of these rules in out-of-the-sample data.

This paper tests whether the most popular technical rule - the moving average - generates profits ir the Madrid Stock Exchange by utilizing genetic algorithms to optimise the rule in the in-sample period (May 1990- May 1995) and applying it to the out-sample period (May 1995 - May 1996, over 25 stocks and indexes. We report the lack of utility, even before transaction costs, of this popular technical rule.
\end{abstract}

\section{Keywords}

trading rules, moving average, genetic algorithms, Madrid Stock Exchange

\section{JEL codes}

G14, C63, C61 



\section{1.- INTRODUCTION}

"One can never prove the statement that past return cannot be used to predict future returns since there are an infinite number of ways that the sequence of past prices can be used to forecast futures prices. All that can be done is to test particular ways of combining past price data to predict future returns".

Elton and Gruber (1984).

That is what we try to do in this paper, to test whether a particular way of combining past prices, what is what moving average rules do, is useful to beat the market.

Technical analysis has been applied by practitioners since long time ago, it is probably as old as the stock market itself. The first studies about technical indicators (focussed on correlations analysis of stock price time series) appeared around 1930. However, is in the sixty's decade, when this body of literature take shape, being developed the "efficient market hypothesis" (EMH) framework. The EMH has important implications for technical analysis, as the weak form of EMH supports he idea that the examination of the sequence of historical prices is worthless to forecast future prices in the market, what means the rejection of trading rules based on past prices, included moving average rules.

Although the classical literature concluded that markets are efficient in its weak form, some recent papers provides evidence of the forecast ability of technical indicators. Brock et al. (1992) is probably the most popular quote in most of the papers analysing technical rules, and particularly moving average rules. Although Brock et al (1992) do not consider transaction costs, their results for the Dow Jones Index are consistent with the predictive power of both technical rules, moving average and trading range break. They find that buy signals, generated by the technical rules, consistently produce higher returns and less volatility than sell signals, and further, returns following sell signals are negative, what is contradictory with equilibrium market models.

A recent body of work has applied evolutionary algorithms to the design of trading rules [see Karjalainen (1994) and Allen and Karjalainen (1999) for genetic programming models of trading and Fernandez et al (2001) and Nuñez-Letamendia (2002) for genetic algorithms models]. The basic approach of these studies is to choose trading rules based on an optimisation procedure using in-sample-data and then testing the performance of these rules in out-of-the-sample data. We follow this body of literature to test the forecast ability of moving average rules in the Madrid Stock Market.

To test the profitability of moving average crossover rule, we build a genetic algorithm model which function is to optimise the moving averages - the length of each one of the two moving averages, which crossing is used to generate trades. In this way, the parameter for the moving average is chosen by the own system, instead by the researcher, avoiding data-snoopy problems. In this system, a buy signal or long position 
is generated if the short-term moving average of prices (SMAt) is greater than the longterm moving average of prices (LMAt), and a short position is hold if the LMAt is above the SMAt.

Short positions:

$$
\left[1 / s \sum_{i=1}^{s} P_{t-i}\right] \leq\left[1 / l \sum_{i=1}^{l} P_{t-i}\right]
$$

Long positions:

$$
\left[1 / l \sum_{i=1}^{l} P_{t-i}\right] \leq\left[1 / s \sum_{i=1}^{s} P_{t-i}\right]
$$

being $\mathrm{s}$ and 1 selected by the genetic algorithm in the in-sample period

The paper is organised as follows: Section 2 presents the data and the genetic algorithm model used to optimise the moving average rules. In section 3 we study the empirical results obtained through our model in in-sample and out-sample periods. Finally, section 4 offers some concluding comments.

\section{2.- DATA AND MODELS}

\section{A. Data}

The data series used in this study comprise a sample of daily prices for 23 stocks and 2 indexes from the Madrid Stock Exchange (MSE). The stocks and indexes in the sample are: Banco BBV, Dragados, Endesa, Repsol, Banco Santander, Unión Fenosa, Viscofan, Cantábrico, Ence, Eléctricas Reunidas de Zaragoza, Tabacalera, Bankinter, Cubiertas, General Index, Metrovacesa, Acerinox, Gesa, Iberdrola, Sevillana, Banco Popular, Telefónica, Vallehermoso, Acesa, Foccsa, and Ibex35.

We use data from the $29^{\text {th }}$ May 1990 to the $15^{\text {th }}$ May 1995 , 1,232 trading days, to optimise the moving average rules for every stock and index (a whole of 30,800 point data for all the sample: $1,232 \times 25$ stocks or indexes). In addition we use data from the $16^{\text {th }}$ May 1995 to the $15^{\text {th }}$ May 1996, 251 trading days, as out-sample period to test the forecast ability of "genetically" optimised moving average rules, (6,275 point data for all the sample).

\section{B. Model}

Genetic algorithm methodology has been applied to a wide variety of problems in the financial field, such as: prediction of bond market (Murray R., 1995), forecasting financial distress (Varetto, 1998), forecasting interest rates (Ju et al. 1997), modelling foreign exchange markets (Neely et al., 1999), designing security trading systems (Karjalainen et al., 1994; Bauer, 1994; Allen et al.,1999; Fyfe et al., 1999; Fahlenbrach, 2002), forecasting market volatility (Neely et al. 2002), EMH analysis (Chen and Yeh, 1997); or corporate financing choices (Noe et al., 2003). 
As defined by Koza (1992), "The genetic algorithm simulates Darwinian evolutionary processes and naturally occurring genetic operations on chromosomes." .."The genetic algorithm is a highly parallel mathematical algorithm that transforms a set (population) of individual mathematical objects (typically fixed-length character strings patterned after chromosome strings), each with an associated fitness value, into a new population (i.e. the next generation) using operators patterned after the Darwinian principle of reproduction and survival of the fittest and after naturally occurring genetic operations..".

The genetic algorithm starts to work by selecting a random sample of potential solutions to the problem to be solved - previously the problem has to be formulated in vectorial or chromosomical notation. In a second step the fitness value of every chromosome (potential solution) - in accordance with an objective function that classifies the solutions from the best to the worst - is computed. The third step applies the reproduction operator to the initial set of potential solutions, through what individuals with higher fitness values are more largely reproduced. There are different selection methods to perform reproduction in the genetic algorithm - to choose the individuals that will create offspring for the next generation. One of the most common method and the one used in this paper is the "roulette wheel" (see Goldberg 1989). This method is equivalent to a fitness-proportionate selection method for populations big enough. Rather than work with the raw fitness of an individual ith, $r f(i)$, to carry out the reproduction process, it is more useful to work with normalized fitness functions, $\mathrm{f}(\mathrm{i})$ :

$$
\begin{gathered}
f(i)=\frac{r f(i)}{\sum_{i=1}^{n} r f(i)} \\
\text { where } \sum_{i=1}^{n} r f(i)=1
\end{gathered}
$$

and $\mathrm{n}$ is the number of individuals in the population of the genetic algorithm.

In a forth step the genetic algorithm applies the crossover and mutation operators, where information of the former offspring is exchanged and mutated to finish the process of generation of a new population of individuals (a new generation of potential solutions). At this point, iterative repetition of steps second to forth take place until the fitness value of populations converge or until a fixed-number of times (what is called the number of generations that the genetic algorithm is run). Figure 1 shows the "modus operandi" of a genetic algorithm. 


\section{Figure 1: Genetic algorithm procedure}

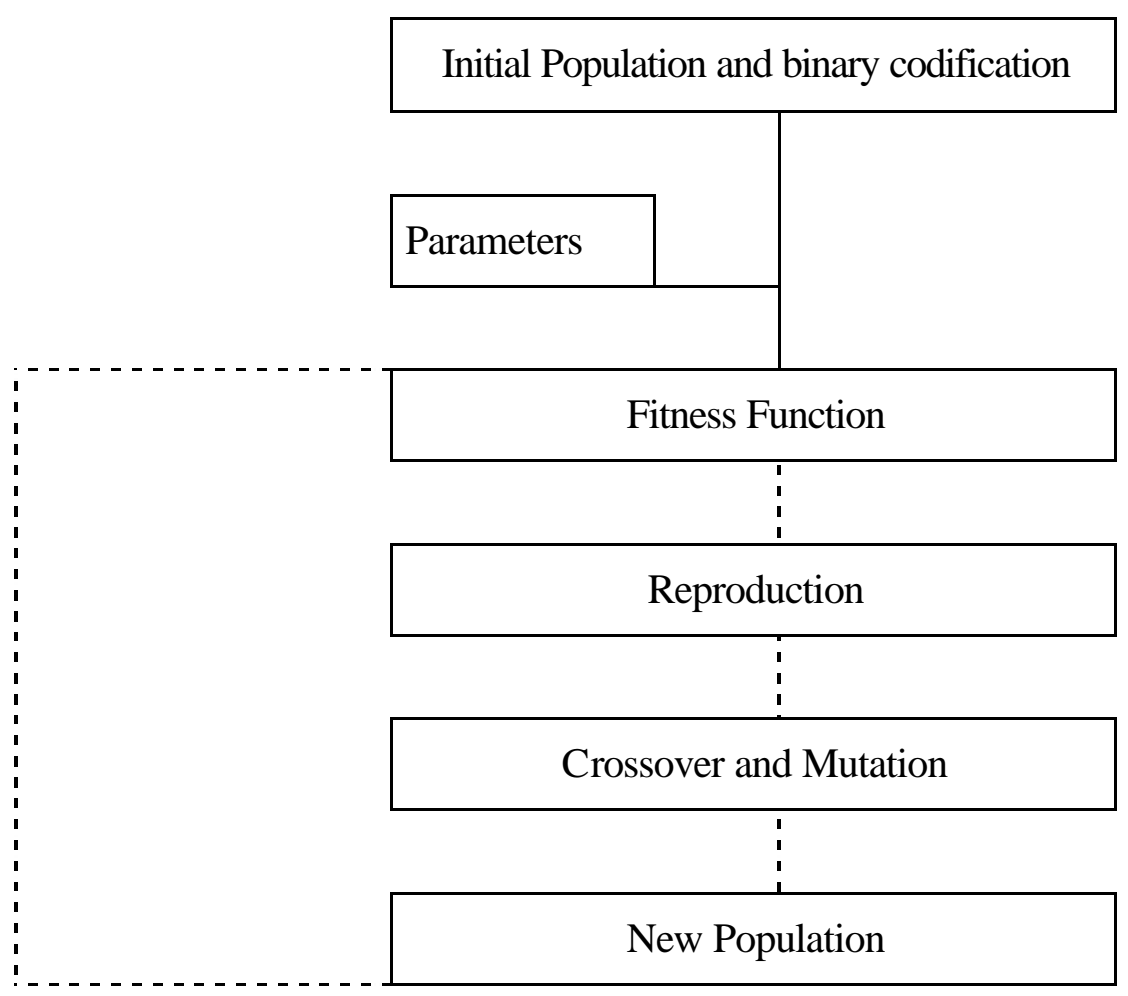

We use a genetic algorithm programmed in $\mathrm{C}$ to optimise technical trading rules based on moving averages crossing. What the genetic algorithm does is to find the number of sessions (the length) that have to be used in each moving average with the aim of maximizing the accumulated return ${ }^{1}$ obtained by the rule in the training period. The ranges allowed for the length of the moving averages are 1-64 and 1-256 sessions ${ }^{2}$. These ranges lead to 16,384 different rules. Figure 2 presents the main features of the genetic algorithm built.

\footnotetext{
${ }^{1}$ See the equations presented in figure 2.

${ }^{2}$ When both moving averages are built with 1 session, the system follows the strategy of buy and hold. If only one of the moving averages is built with 1 session, the rule is the crossing of one moving average with the stock price. If both moving averages are built with the same length, then the rule is the crossing of the moving average of this length with the stock price.
} 
Figure 2: Features of our genetic algorithm

a.- Concatenated chromosomes with binary codification, which represent two variables: the number of sessions to be used in each of the two moving averages. The number of genes of these variables depends on the size allowed for the lengths of the moving averages. For a length of 64 , six genes are needed when binary codification is use $\left(2^{6}=64\right)$; for a length of 256, 8 genes are needed $\left(2^{8}=256\right)$ :

$$
\text { chromosomes' type } \quad(110101,01011110)
$$

b.- The fitness function is the accumulated return generated by the trading rule constructed by

$$
\begin{gathered}
A R_{f}=\prod_{i=1}^{f}\left(1+D R_{i}\right) \\
D R_{i}=\frac{P_{i}-P_{i-1}}{P_{i-1}} \times \delta
\end{gathered}
$$

$A R_{f}$ is the accumulated return at the end of the sample period; $D R_{i}$ the daily return at day i; $P_{i}$ denotes the stock price at day $\mathrm{i}$; and $\delta$ is a dummy variable that takes the value of 1 for buy signals (long positions) and ( -1 ) for sale signals (short positions).

c.- The reproduction operator is applied by the roulette algorithm (see Goldberg 1989).

d.- Binary crossover and mutation operators with proportions of $60 \%$ of the individuals and $0.5 \%$ of the genes are implemented.

e.- The number of individuals in each generation is set to 50 , equivalent to $0.3 \%$ of the total population which comprises 16,384 individuals (or different rules) and the number of generations is set to 50 .

We use four different versions of the same genetic algorithm (with different design parameters), that are running over every stock in the sample: Model 1 is designed with the parameters and features described in figure 2. Model 2 changes the population size from 50 to 100 and the number of generation to 25, instead 50. Models 3 and 4 are the same that model 1 and 2 respectively, but with the introduction of a scaling process in the fitness function: During the initial phase of the genetic algorithm run, it is frequent that exceptionally good potential solutions arise. If their reproduction is not regulated, these solutions would greatly reproduce themselves and could lead to a problem of premature convergence to a local optimum. Scaling of the fitness function is one of the available tools to solve this problem, in the sense that it controls the reproduction of solutions, thus impeding the best ones to excessively reproduce themselves or the worst ones to prematurely be lost in the first generations of the genetic algorithm. At the same time, scaling increases the differentiation between good solutions in the final phases of the genetic algorithm run, thus reproducing the best ones more than what would occur in accordance with their fitness values. 
Scaling methods are based on algorithms that map raw fitness values keeping the selection pressure relatively constant along the generations of the genetic algorithm, rather than focus in the fitness variance of the population ${ }^{3}$.

We use the scaling process proposed by Goldberg (1989). The individual's reproduction is given by $R(i, t)$ :

$$
\begin{array}{lll}
R(i, t)= & 1+\frac{f(i)-f *(t)}{2 s(t)} & \text { if } s(t) \neq 0 \\
R(i, t)= & 1 & \text { if } s(t)=0
\end{array}
$$

Where $R(i, t)$ is the expected value for each individual, $f(i)$ is the fitness of the individual $i, f *(t)$ is the average fitness of population and $s(t)$ is the population standard deviation.

\section{3.- Simulation ReSUlts}

Each genetic model is run one time for every stock or index in the sample over the training period. Then, the best rule (the best crossing moving average) is selected from each one of the models for every stock (see table 1) and applied to the out-sample period. To analyse the forecast ability of the rules selected by the genetic models we compute the accumulated returns and standard deviations obtained by the models in the out-sample period as reported in table 2. T-test comparing buy-and-hold returns and genetic strategy returns are reported in the last row of table 2 .

Accumulated returns before and after transaction cost are show in table 2. However, as can be seem from the table, returns (before transaction cost) obtained by the moving averages optimised by the genetic models are quite below the buy-and-hold return, with statistical significance (at 95\%) for the genetic models 1 and 2. Such results are even worse when the risk factor is taken into account, as the risk level supported by the genetic strategies is almost the same that for the buy-and-hold strategy, as can be seen computing the Sharpe ratios. Taking into account transaction cost, return obtained by three of the four models is below return from buy and hold strategy. This results show the lack of forecast ability of moving average indicators for the Spanish market.

\footnotetext{
${ }^{3}$ Goldberg (1989) points out that the regulation of reproduction is especially important in small population (50-100 individuals), fixing the number of offsprings between 1,2 and 2 for the best individual of the generation.
} 


\section{Table 1: Results from training}

This table reports the length of the moving averages (short and long) chosen by each of the four genetic algorithm models for every stock in the sample. Figures in bold face denote the rules that do not follow the guidelines of technical analysis theory, but the contrary. Technical analysis rules point out large positions (buy) when the shorter moving average is above the longer, and short positions (sell) in the opposite situation. When both moving averages are built with 1 session, the system follows the strategy of buy and hold. If only one of the moving averages is built with 1 session, the rule is the crossing of one moving average with the stock price. If both moving averages are built with the same length, then the rule is the crossing of the moving average of this length with the stock price.

\begin{tabular}{|l|cc|cc|cc|cc|}
\hline \multicolumn{1}{|c|}{ Stocks } & \multicolumn{2}{c|}{ Model 1 } & \multicolumn{2}{c|}{ Model 2 } & \multicolumn{2}{c|}{ Model 3 } & \multicolumn{2}{c|}{ Model 4 } \\
\hline ACESA & 10 & 113 & 15 & 112 & 17 & 19 & 16 & 106 \\
ACERINOX & 2 & 32 & $\mathbf{5 9}$ & $\mathbf{4 6}$ & 5 & 20 & 2 & 9 \\
BBV & $\mathbf{5 2}$ & $\mathbf{2 2}$ & $\mathbf{4 3}$ & $\mathbf{9}$ & $\mathbf{4 4}$ & $\mathbf{2 1}$ & $\mathbf{3 3}$ & $\mathbf{9}$ \\
BANKINTER & 25 & 58 & 18 & 89 & 1 & 2 & 31 & 77 \\
CANTABRICO & 17 & 24 & 13 & 100 & 22 & 78 & 16 & 21 \\
CUBIERTAS & 11 & 25 & 1 & 36 & 2 & 13 & 9 & 29 \\
DRAGADOS & 1 & 51 & 1 & 51 & 28 & 31 & 1 & 47 \\
ENDESA & 11 & 75 & 14 & 76 & 8 & 84 & 15 & 73 \\
ENCE & 4 & 22 & 16 & 27 & 16 & 24 & 1 & 5 \\
ERZ & 3 & 127 & 6 & 126 & 6 & 119 & 6 & 75 \\
FOCSA & 26 & 42 & 19 & 55 & $\mathbf{6 3}$ & $\mathbf{6 2}$ & 30 & 37 \\
GESA & 28 & 60 & 45 & 51 & 43 & 54 & 9 & 96 \\
IBERDROLA & 6 & 105 & 2 & 14 & 20 & 41 & 25 & 32 \\
IBEX-35 & 11 & 62 & 1 & 3 & 2 & 3 & 1 & 97 \\
IGE & 16 & 17 & 1 & 21 & 5 & 19 & 14 & 16 \\
METROVACESA & 10 & 38 & 11 & 26 & 14 & 22 & 13 & 39 \\
POPULAR & 45 & 118 & 45 & 97 & 11 & 16 & 38 & 38 \\
REPSOL & $\mathbf{5 3}$ & $\mathbf{5 1}$ & 28 & 103 & 17 & 105 & 1 & 5 \\
B. SANTANDER & 1 & 2 & 3 & 13 & $\mathbf{3 5}$ & $\mathbf{2 5}$ & 1 & 12 \\
SEVILLANA & 2 & 65 & 4 & 70 & 15 & 50 & 9 & 19 \\
TABACALERA & 23 & 54 & 1 & 4 & 62 & 66 & 19 & 58 \\
TELEFÓNICA & $\mathrm{c}$ & $\mathrm{m}$ & 48 & 48 & 15 & 153 & 44 & 212 \\
UNIÓN FENOSA & 1 & 31 & 2 & 15 & 1 & 32 & 1 & 31 \\
VALLEHERMOSO & 61 & 102 & 3 & 17 & 1 & 5 & 6 & 18 \\
VISCOFÁN & 13 & 79 & 10 & 80 & 6 & 85 & 9 & 85 \\
\hline
\end{tabular}


Table 2: Results (out-sample period)

\begin{tabular}{|c|c|c|c|c|c|c|c|c|c|c|c|c|c|c|}
\hline & r_b\&h & st_d_b\&h & r_m1 & st_d_m1 & r_m1cost & r_m2 & st_d_m2 & r_m $2 \cos t$ & r_m3 & st_d_m3 & r_m3cost & r_m4 & st_d_m4 & r_m4 cost \\
\hline ACESA & 0.12766 & 0.01421 & -0.24358 & 0.01419 & -0.25695 & -0.34460 & 0.01414 & -0.35635 & -0.35596 & 0.01413 & -0.41629 & -0.29917 & 0.01416 & -0.31174 \\
\hline ACERINOX & -0.01601 & 0.01907 & 0.12134 & 0.01906 & 0.03271 & -0.00437 & 0.01907 & -0.02598 & 0.27933 & 0.01903 & 0.22195 & 0.30895 & 0.01902 & 0.16330 \\
\hline BBV & 0.39143 & 0.00931 & -0.07927 & 0.00940 & -0.09586 & -0.11132 & 0.00940 & -0.13419 & -0.08926 & 0.00940 & -0.11288 & -0.13483 & 0.00939 & -0.15711 \\
\hline BANKINTER & 0.24189 & 0.01032 & -0.15264 & 0.01035 & -0.17771 & 0.04331 & 0.01036 & 0.02050 & 0.29681 & 0.01031 & -0.16975 & -0.17557 & 0.01034 & -0.20003 \\
\hline CANTABRICO & 0.07612 & 0.01043 & -0.10217 & 0.01043 & -0.15960 & -0.19386 & 0.01041 & -0.20828 & -0.27261 & 0.01037 & -0.28572 & -0.04347 & 0.01044 & -0.11162 \\
\hline CUBIERTAS & -0.10714 & 0.01987 & -0.41264 & 0.01978 & -0.43909 & -0.13893 & 0.01987 & -0.20995 & -0.01156 & 0.01987 & -0.09991 & -0.09332 & 0.01987 & -0.12707 \\
\hline DRAGADOS & -0.05851 & 0.01698 & -0.15830 & 0.01697 & -0.21213 & -0.15830 & 0.01697 & -0.21213 & 0.01878 & 0.01698 & -0.03098 & -0.03421 & 0.01698 & -0.10301 \\
\hline ENDESA & 0.36102 & 0.01322 & -0.05537 & 0.01329 & -0.07966 & -0.15658 & 0.01328 & -0.17834 & 0.10896 & 0.01328 & 0.08930 & -0.04623 & 0.01329 & -0.06331 \\
\hline ENCE & -0.41772 & 0.02379 & -0.07270 & 0.02386 & -0.12213 & 0.64738 & 0.02376 & 0.59256 & 0.89304 & 0.02370 & 0.80807 & 1.76706 & 0.02347 & 1.25400 \\
\hline ERZ & 0.26145 & 0.01069 & 0.18235 & 0.01071 & 0.16155 & 0.06842 & 0.01073 & 0.04936 & 0.18848 & 0.01071 & 0.16750 & 0.25873 & 0.01069 & 0.23628 \\
\hline FOCSA & -0.15033 & 0.01824 & 0.00111 & 0.01825 & -0.01698 & 0.15095 & 0.01823 & 0.13008 & -0.06610 & 0.01825 & -0.12239 & -0.05407 & 0.01036 & -0.09694 \\
\hline GESA & 0.11020 & 0.01015 & -0.13508 & 0.01014 & -0.15734 & -0.21453 & 0.01012 & -0.24078 & -0.19738 & 0.01012 & -0.22429 & -0.20444 & 0.01012 & -0.22494 \\
\hline IBERDROLA & 0.45977 & 0.01407 & 0.35498 & 0.01410 & 0.34161 & -0.08501 & 0.01416 & -0.19694 & 0.09744 & 0.01036 & 0.07804 & 0.47695 & 0.01406 & 0.43909 \\
\hline IBEX-35 & 0.25776 & 0.00846 & 0.11003 & 0.00851 & 0.09022 & -0.00020 & 0.00852 & -0.30131 & -0.16206 & 0.00849 & -0.41468 & 0.21518 & 0.00848 & 0.19344 \\
\hline IGE & 0.20466 & 0.00757 & 0.06650 & 0.00760 & -0.03321 & 0.08422 & 0.00760 & -0.02491 & 0.06651 & 0.00760 & 0.01034 & 0.03399 & 0.00760 & -0.05889 \\
\hline METROVACESA & 0.09499 & 0.01212 & -0.12213 & 0.01212 & -0.15174 & -0.16504 & 0.01211 & -0.20273 & -0.06825 & 0.01212 & -0.12444 & -0.08529 & 0.01212 & -0.11596 \\
\hline POPULAR & 0.22448 & 0.01228 & 0.28588 & 0.01227 & 0.27831 & 0.05322 & 0.01231 & 0.03872 & 0.19038 & 0.01229 & 0.10080 & 0.01013 & 0.01232 & -0.06183 \\
\hline REPSOL & 0.10050 & 0.01053 & 0.05189 & 0.01053 & 0.03327 & 0.00812 & 0.01054 & -0.00219 & 0.08316 & 0.01053 & 0.07240 & 0.23468 & 0.01050 & -0.02267 \\
\hline B. SANTANDER & 0.26850 & 0.01302 & 0.32353 & 0.01300 & -0.17563 & -0.33948 & 0.01296 & -0.40830 & -0.15459 & 0.01304 & -0.17637 & 0.01692 & 0.01305 & -0.00614 \\
\hline SEVILLANA & 0.65909 & 0.01291 & 0.32049 & 0.01303 & 0.27621 & 0.31492 & 0.01303 & 0.28081 & 0.60333 & 0.01293 & 0.55005 & 0.58951 & 0.01294 & 0.53626 \\
\hline TABACALERA & 0.32420 & 0.01641 & 0.33849 & 0.01641 & 0.32515 & 0.25744 & 0.01642 & -0.04825 & -0.14150 & 0.01645 & -0.16373 & 0.29183 & 0.01642 & 0.27882 \\
\hline TELEFÓNICA & 0.38226 & 0.01119 & 0.38226 & 0.01119 & 0.38226 & 0.29262 & 0.01122 & 0.22939 & 0.20206 & 0.01124 & 0.17593 & 0.06810 & 0.01127 & 0.02420 \\
\hline UNIÓN FENOSA & 0.42593 & 0.01229 & 0.10266 & 0.01237 & -0.00834 & 0.18411 & 0.01236 & 0.10024 & 0.09254 & 0.01238 & -0.01753 & 0.10266 & 0.01237 & -0.00834 \\
\hline VALLEHERMOSO & -0.02857 & 0.01564 & -0.30067 & 0.01558 & -0.31319 & 0.03978 & 0.01563 & -0.06114 & 0.67117 & 0.01548 & 0.34358 & 0.12938 & 0.01562 & 0.05252 \\
\hline VISCOFÁN & 0.09348 & 0.02449 & 0.12522 & 0.02449 & 0.09649 & 0.06604 & 0.02449 & 0.03005 & -0.05436 & 0.02450 & -0.07889 & 0.03807 & 0.02449 & 0.01122 \\
\hline Average & 0.17148 & 0.01389 & 0.03729 & 0.01390 & -0.01527 & 0.03372 & 0.01391 & -0.04913 & 0.08873 & 0.01374 & 0.00720 & 0.13486 & 0.01357 & 0.06078 \\
\hline t-test & & & 2.113* & & 2.958* & $2.503 *$ & & $3.548 *$ & 1.112 & & 2.288* & 0.398 & & 1.408 \\
\hline
\end{tabular}




\section{4.- CONCLUDING REMARKS}

Previous studies have reported mixed results with regard to the success of technical trading rules. Studies that provide positive evidence that simple technical trading rules generate valuable signals are [Brock, Lakonishok and Lebaron (1992), Karjalainen, R.E. (1994), Bessembinder and Chan (1995), Mills (1997), and Fernandez et al. (1999)]. Studies rejecting the utility of technical trading rules are [Hudson et al. (1996) or Allen, F. and Karjalainen R.E. (1999)].

Most of the literature ignore the issue of parameter optimisation, thus generating concerns over data-snooping. A recent body of work addressing the criticism mentioned above has applied evolutionary algorithms to the parameter optimisation of trading rules [see Karjalainen (1994) and Allen and Karjalainen (1999) for genetic programming models of trading and Fernandez et al (2001) and Nuñez-Letamendia (2002) for genetic algorithms models]. The basic approach of these studies is to choose trading rules based on an genetic optimisation procedure using in-sample-data and then testing the performance of these rules in out-of-the-sample data.

Following that line, this paper has investigated the profitability of the most popular technical rule - the moving average - over the Madrid Stock Exchange by utilizing genetic algorithms to optimise the rule in the in-sample period (May 1990- May 1995) and applying it $\mathbf{b}$ the out-sample period (May 1995 - May 1996). We test the forecast ability of moving average rule over 25 stocks and indexes quoted at the Madrid Stock Market. We report the lack of utility, even before transaction costs, of this popular technical rule.

To beat the market may require more complicated trading rules, or at least, less known rules: "If a rule is easy to find, it will probably appear as a glaring inefficiency in the market and will promptly be arbitraged away, thereby invalidating it. For example, this may be a reason for the poor returns of simple moving average models in the foreign exchange markets over the last 15 years". (Colin, "Genetic algorithms for financial modelling" in Deboeck, 1994, pag. 149). The analysis of more sophisticated technical strategies may be an interesting topic for future research. 


\section{REFERENCES}

Allen, F. \& Karjalainen R.E. 1999. Using genetic algorithms to find technical trading rules. Journal of Financial Economics, ${ }^{\circ}$ 51, pag. 245-271.

Bauer, R.J. 1994. Genetic algorithms and investment strategies. John Wiley.\& Sons, Inc.

Bessembinder, H. \& Chan, K. 1995. The profitability of technical trading rules in Asian stock markets. Pacific Basin Finance Journal, 3, p.257-284

Brock, W., Lakonishok, J. \& LeBaron. 1992. Simple technical rules and stochastic properties of stock returns. Journal of Finance vol. XLVII, n5, December 1992, pag. 17311764.

Chen, Shu-Heng, Yeh, Chia-Hsuan 1997. Toward a computable approach to the efficient market hypothesis: An application of genetic programming. Journal of Economic Dynamics \& Control. Amsterdam: Jun 1, 1997. Vol. 21, Iss. 6; p. 1043 (21 pages)

Colin 1994. Genetic algorithms for financial modeling in Deboeck [Trading on the edge],1994, pag. 149

Elton, E.J., \& Gruber, M.J. 1984. Modern Portfolio Theory and Investment Analysis. $2^{\circ}$ edition. John Wiley \& Sons.

Fahlenbrach R. \& Strobl, G 2002. Using Genetic Algorithms to find technical trading rules: an asset-allocation perspective, Working Paper: Finance Department, The Wharton School, University of Pennsylvania.

Fernandez, F., Gonzalez, C. \& Sosvilla, S. 2001. Optimisation of technical rules by genetic algorithms: Evidence from the Madrid sctock market. DT 2001-14-FEDEA. Madrid.

Fyfe, C., Marney, J.P., \& Tarbert, H. 1999. Technical analysis versus market efficiency - a genetic programming approach. Applied Financial Economics, 9, Iss.2, pag.183-191.

Goldberg, D.E. 1989. Genetic algorithms in search, optimization and machine learning. Addison-Wesley. Reading, Massachusetts.

Hudson, R., Dempsey, M. \& Keasey, K. 1996. A note on the weak form efficiency of capital markets: The application of simple technical trading rules to UK stock prices - 1935 to 1994. Journal of Banking and Finance 20, 1996, pag. 1121-1132.

Ju Y J, Kim, C E, Shim, J C., 1997. Genetic-based fuzzy models: Interest rate forecasting problem, Computers \& Industrial Engineering, Vol. 33, Iss. 3,4; p. 561.

Karjalainen, R.E. 1994. Using genetic algorithms to find technical trading rules in financial markets. Disertation Abstracts International. University Microfilms International. MI-USA.

Koza, J.R. 1992. Genetic Programming: On the programming of computers by means of natural selection. MIT Press, Cambridge, Massachusetts. 
Ki-Yeol Kwon, Richard J Kish. 2002. Technical trading strategies and return predictability: NYSE. Applied Financial Economics, Vol. 12, Iss. 9; p. 639

Ki-Yeol Kwon, Richard J Kish. 2002. A comparative study of technical trading strategies and return predictability: An extension of Brock, Lakonishok, and LeBaron (1992) using NYSE and NASDAQ indices. Quarterly Review of Economics and Finance. Greenwich: Vol. 42, Iss. 3; p. 611

Murray,R. 1995. Taking evolution into warp speed, Futures, Vol. 24, Iss. 9; p. 42

Mills, T. 1997. Technical analysis and the London Stock Exchange: testing trading rules using the FT30. International Journal of Finance and Economics, 2, 319-331.

Neely C.J. \& Weller, P.A., 1999. Technical trading rules in the European Monetary System, Journal of International Money and Finance, Vol. 18, Iss. 3; p. 429

Noe T., Rebello, M., \& Wang, J. 2003. Corporate financing: an artificial agent-based analysis, Journal of Finance, V 58, 3, 943- 973.

Nuñez-Letamendia, L. 2002. Trading systems designed by genetic algorithms. Managerial Finance, V 28, nº 8, p. 87-106.

Vareto, F. 1998. Genetic Algorithms applications in the analysis of insolvency risk. Journal of Banking and Finance 22, Elsevier, pag. 1421-39. 
NOTAS

ב 
NOTAS

ב 
NOTAS 